\title{
Efficiency of modified radical mastectomy in the therapeutic conduct of breast cancer
}

\author{
ANDREI MOISIN ${ }^{1}$, GEORGE MANDA ${ }^{2}$, DAN GIORGIAN BRATU ${ }^{1,3}$, DRAGOS SERBAN ${ }^{4,5 *}$, \\ CATALIN GABRIEL SMARANDACHE ${ }^{4,5}$, CATALINA MOTOFEI ${ }^{6}$, CIPRIAN TĂNĂSESCU $^{1,3}$ \\ ${ }^{1}$ Sibiu County Clinical Emergency Hospital, Sibiu, Romania \\ ${ }^{2}$ County Clinical Emergency Hospital of Cluj-Napoca, Romania \\ ${ }^{3}$ Clinic Surgical Department, "Lucian Blaga" University Sibiu, Romania \\ ${ }^{4}$ Faculty of Medicine, "Carol Davila" University of Medicine and Pharmacy, \\ Bucharest, Romania \\ ${ }^{5} 4^{\text {th }}$ Surgery Department, Emergency University Hospital Bucharest, Romania \\ ${ }^{6}$ ASE Bucharest, statistics, analysis evaluation, Bucharest, Romania
}

\begin{abstract}
Breast cancer is the most common form of malignant tumour in females, its frequency being constantly increasing and being the second cause of mortality, after lung cancer, in women. The objective of the study is to evaluate the efficacy, performance and safety of modified radical mastectomy in clinical and technical terms in patients with breast cancer.

Method and Results: A 5 year retrospective study was performed on the patients who underwent surgery for breast cancer. Of the 129 patients aged between 20 and 99 years, the maximum incidence is observed in the age group 60-69 years. The most used surgical procedures were: modified radical mastectomy (MRM) in 48 cases and sectorectomy in 32 cases. Madden type of MRM was performed in $95.83 \%$, with no major intra or postoperative complications.

Conclusions: Modified radical mastectomy is the first-choice surgery for patients diagnosed with breast cancer in more advanced stages of this disease, compared to conservative therapy which is indicated in the early stages of the disease. Active prophylaxis of surgical site infections was extremely important to achieve good cosmetic results of the surgical wound.
\end{abstract}

Keywords Breast cancer, Madden mastectomy, surgical treatment, surgical site infections.

To cite this article: MOISIN A, MANDA G, BRATU DG, SERBAN D, SMARANDACHE CG, MOTOFEI C, TĂNĂSESCU C. Efficiency of modified radical mastectomy in the therapeutic conduct of breast cancer. Rom Biotechnol Lett. 2021; 26(1): 2331-2339. DOI: $10.25083 / \mathrm{rbl} / 26.1 / 2331.2339$ 


\section{Introduction}

Breast cancer is a pathology with increased variability depending on the hormonal package, genetics or possible depending on the hormonal package, genetics or possible comorbidities of patients that influence its evolution. Studies have shown that it can take several years for the clinical or imaging diagnosis of the neoplasm with a more favourable postoperative prognosis if the tumour is discovered in its preclinical stages (ANGELESCU \& al [1]).

Over time, multiple surgical treatment strategies for breast cancer have been established, this study addressing modified radical mastectomies and conservative treatment. Modified radical mastectomy is a fundamental surgical technique because the invasion of the malignant process at breast level takes place simultaneously in multiple foci, regardless of the size of the initial tumour (MITULESCU \& al [2]).

The emergence and development of surgical methods has allowed the access to the establishment of multiple therapeutic strategies to treat breast cancer. The modified radical mastectomy has a special place, the Madden type being sovereign to the other modified radical mastectomies, due to its less disabling nature, favourable results, as well as the low number of postoperative recurrences compared to other conservative non-surgical and surgical therapies.

This paper aims at presenting the efficiency of modified radical mastectomy within the surgical treatment of breast cancer, performed in the Surgery Clinic II of the Sibiu County Emergency Clinical Hospital and at discussing the results obtained, related to the long practice of other medical services and to international specialized literature.

The aim of the paper is to evaluate the importance and necessity of approaching a surgical treatment such as modified radical mastectomy in patients diagnosed with breast cancer. The objective of the study is to evaluate the efficacy, performance and safety of modified radical mastectomy in clinical and technical terms in patients with breast cancer. The study also aims to follow the aspects and results obtained in the modified radical mastectomy applied for the purpose of treating breast cancer, as well as its indications from the perspective of histopathological examination. Another objective is to analyse the relationship of modified radical mastectomy with other types of surgery applied to this disease, mainly targeting sectorectomy, and to compare modified radical mastectomy with conservative surgical treatment by analysing histopathological examination, complications, age, length of hospital stay and tumour location.

\section{Materials and Methods}

This study is a retrospective one with a descriptive character, being based on a complex analysis of data and materials for clinical and paraclinical observation of patients diagnosed with breast cancer in the Surgery
Clinic II of the Sibiu County Emergency Clinical Hospital, for a period of 5 years, between 2013 and 2017. The study was performed by accessing the computerized database of the Sibiu County Emergency Clinical Hospital.

Within this study, a general group (group G) was selected, which included a number of 129 patients diagnosed with breast cancer in the Surgery Clinic II of the Sibiu County Emergency Clinical Hospital. From this general group, a main group (group A) consisting of 48 patients who received modified radical mastectomy surgery and a secondary group (group B) consisting of 43 patients were selected, of which 32 cases had were treated by sectorectomy, and 11 cases benefited from tumorectomy. The rest of the cases, in number of 38 patients, were hospitalized in order to perform a breast biopsy. The casuistry included patients hospitalized and diagnosed with breast cancer between 28.03.2013 21.12.2017.

Among the parameters aimed at in the evaluation of patients belonging to the general group (group $\mathrm{G}$ ), we can mention: age, patient gender, their distribution by counties, distribution by year of cases diagnosed with breast cancer and the types of surgery.

Regarding the evaluation of patients belonging to the main group (group A), the following parameters such as: types of radical mastectomies, anatomical location of the tumour, histopathological diagnosis, anatomical and pathological aspects of tumours, pTNM stage-degree of differentiation and resection margins, duration of hospitalization, cases that benefited from neoadjuvant treatment, age, lymph node dissection, types of incisions and immunohistochemical examination were followed.

The parameters followed in the evaluation of patients belonging to the secondary group (group B), included in the study referred to the histopathological examination, the duration of hospitalization and the age of the patients. Also, this study analysed the frequency and nature of intraoperative and postoperative complications.

The study included all the cases that benefited from surgical treatment in the Surgery Clinic II of the Sibiu County Emergency Hospital as well as the cases confirmed from the histopathological point of view with the diagnosis of malignant breast tumour. Cases that do not belong to the Surgery Clinic II of the Sibiu County Emergency Hospital, cases confirmed clinically and paraclinically with the diagnosis of benign breast tumour, cases diagnosed with acute breast infections (breast abscess, tuberous breast abscess, premammary abscess, retromammary abscess, puerperal mastitis) or other cases diagnosed with breast lesions were excluded from this study (epidermoid cyst, galactocele, retroareolar cyst, Mondor disease, fibrocystic mastosis, Phyllodes tumour).

For the statistical analysis, Microsoft Excel Office 365 software was used for the statistical calculation. The differences were considered significant if $p<0.05$. Based on the collected data, the analysis and comparison of the cases that were represented with the help of tables and figures was prepared. 


\section{Results and Discussion}

\section{Presentation of the general group (group G)}

The overall group includes all patients considered in the present study $(\mathrm{n}=129)$.

The analysis of the distribution of cases between 2013 and 2017 shows that the number of hospitalizations for breast cancer is increasing with an average of about 8 cases per year. Regarding the statistical analysing, for the incidence of patients diagnosed with breast cancer during this period, a $p$ value of 0.00019 was obtained, a statistically significant value, taking into account the standard value $p<0.05$.

Table 1. Distribution of patients for the period 2013-2017

\begin{tabular}{|c|c|c|}
\hline Year & $\begin{array}{c}\text { Number of patients } \\
(\mathbf{n = 1 2 9})\end{array}$ & $\begin{array}{c}\text { Percentage } \\
(\boldsymbol{\%})\end{array}$ \\
\hline 2013 & 8 & $6,20 \%$ \\
\hline 2014 & 16 & $12,40 \%$ \\
\hline 2015 & 24 & $18,60 \%$ \\
\hline 2016 & 36 & $27,90 \%$ \\
\hline 2017 & 45 & $34,88 \%$ \\
\hline
\end{tabular}

Of the 129 patients aged between 20 and 99 years, the maximum incidence is observed in the age group 60-69 years (41 patients, representing a percentage of $31.78 \%$ of all cases), followed in descending order by the following age groups: 50-59 years (38 patients), 70-79 years (20 patients), 40-49 years (15 patients), 80-89 years (10 patients), 20-29 years (2 patients), 30-39 years ( 2 patients) and 90-99 years (1 patient). The statistical analysis revealed a $\mathrm{p}$ value of 0.00031 .

The distribution of cases by counties and the origin environment of the general group is presented in Table 2. The statistical significance is demonstrated by the value of $p=0.027$. The majority of patients included in this group come from urban areas (84 cases, $65.12 \%)$ and the rest of them from rural areas (45 cases, $34.88 \%$ ).

Table 2. Distribution of patients by counties

\begin{tabular}{|c|c|c|}
\hline County & Number of cases & Percentage (\%) \\
\hline Alba & 7 & $5,43 \%$ \\
\hline Braşov & 4 & $3,10 \%$ \\
\hline Gorj & 2 & $1,55 \%$ \\
\hline Mureș & 4 & $3,10 \%$ \\
\hline Sibiu & 99 & $76,74 \%$ \\
\hline Vâlcea & 13 & $10,08 \%$ \\
\hline
\end{tabular}

The patients of the general group were divided into 2 groups according to gender. 125 cases of female gender, respectively $96.89 \%$ and 4 cases of male gender, respectively $3.11 \%$, diagnosed with breast cancer were reported.

Among the types of surgeries, the most frequent were modified radical mastectomy (MRM) and sectorectomy (Table 3). Of note is the ratio between the modified radical mastectomy and the sectorectomy which was $48 / 32$.

Table 3. Types of surgical interventions

\begin{tabular}{|l|c|c|}
\hline Type of intervention & $\mathbf{N r}$ & Percentage (\%) \\
\hline MRM & 48 & $37,21 \%$ \\
\hline Sectorectomy & 32 & $24,81 \%$ \\
\hline Tumorectomy & 11 & $8,53 \%$ \\
\hline Breast biopsy & 38 & $29,45 \%$ \\
\hline
\end{tabular}

\section{Presentation of the main group (group A)}

This group includes patients diagnosed with breast cancer who benefited from modified radical mastectomy $(\mathrm{n}=48 ; 37.21 \%)$. The preferred surgery was Madden modified radical mastectomy (46 cases, 95.83\%). This emphasizes the superiority of Madden surgery over other types of modified radical mastectomies (Figure 1).

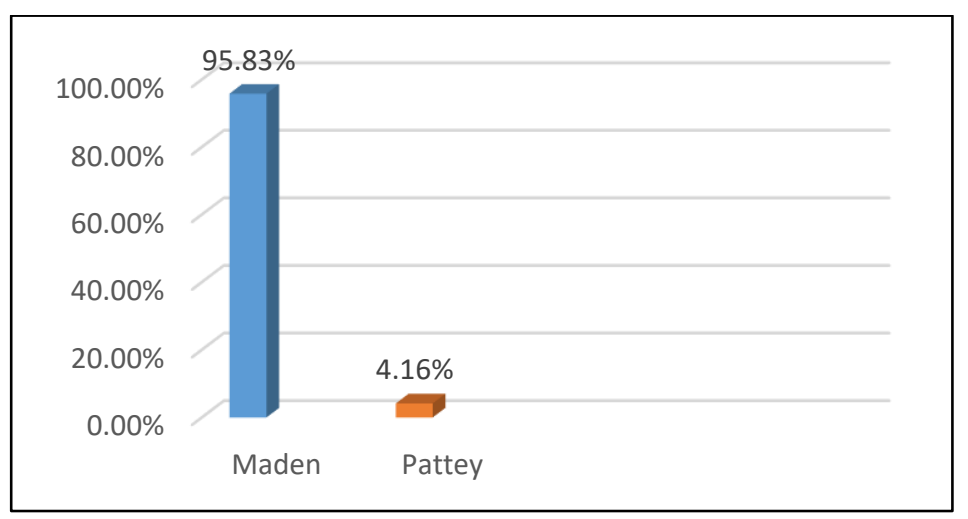

Figure 1. Percentage of the types of modified radical mastectomies performed in Surgery Clinic II of the Sibiu County Clinical Emergency Hospital.

An important parameter followed in the patients belonging to this group is the duration of their hospitalization following a modified radical mastectomy. Following the analysis of statistical data, it can be noticed that for most patients treated by modified radical mastectomy the duration of hospitalization was 7/8/9 days, respectively $22.92 \% / 29.17 \% / 12.50 \%$. The shortest hospital stay was 4 days and the longest was 33 days. 
Another important parameter followed in patients belonging to this group is the type of incision. Modified radical mastectomies were initiated by Orr or Stewart incisions. Among the patients who benefited from this intervention, in 39 interventions the oblique incision Orr was performed $(81.25 \%)$, and in 9 interventions the Steward's transverse incision was performed (18.75\%). An important aspect from an oncological point of view is that in all the cases in which the modified radical mastectomy was performed, the axillary dissection was performed. After the surgery, the axillary drainage and the subcutaneous drainage were established at the breast level, placed anteriorly to the pectoralis major, under the skin flap. It was performed for all modified radical mastectomies.

The patients of the main group (group A) were analysed according to the presence or abscess of intraand postoperative complications. During the 5 years included in this study, there were no intraoperative complications and no major postoperative complications or deaths occurred (Table 4). Regarding the cases that benefited from preoperative oncological treatment, out of the total of group A, only 13 cases $(27.08 \%)$ performed neoadjuvant chemotherapy treatments, and 2 cases $(4.16 \%)$ performed hormone therapy treatments, being hospitalized afterwards in the Surgery Clinic II for specialized treatment.

Table 4. Distribution of patients according to intra- and postoperative complications

\begin{tabular}{|c|c|c|c|}
\hline \multicolumn{2}{|c|}{ Complications } & $\begin{array}{c}\text { Number of cases } \\
(n=48)\end{array}$ & $\begin{array}{l}\text { Statistical analysis } \\
\text { (p) }\end{array}$ \\
\hline \multicolumn{2}{|c|}{ Intraoperative } & 0 & - \\
\hline \multirow{4}{*}{ Postoperative } & hematoma & $1(2.08 \%)$ & \multirow{4}{*}{0,1134} \\
\hline & seroma & $5(10.42 \%)$ & \\
\hline & $\begin{array}{c}\text { wound } \\
\text { dehiscence }\end{array}$ & $2(4.17 \%)$ & \\
\hline & ulceration/cell & $1(2.08 \%)$ & \\
\hline
\end{tabular}

The patients in the main group were distributed according to the location of the primary tumour at the level of the breast quadrants. The distribution of malignant tumours shows a dominance of tumour localization in the supero-external quadrant (23 cases), followed in descending order by those with localization in: central quadrant (9 cases), infero-external quadrant (6 cases), infero-internal quadrant (4 cases), several quadrants simultaneously (3 cases), the supero-internal quadrant ( 2 cases) or the whole glandular parenchyma with 1 case. The statistical analysis is significant with $p=0.017$.

Staging of breast cancer is done according to the TNM system, with a post-surgical classification, which includes a tumour component, a lymph node and a metastatic component. Tumoral and lymph node stages encountered in the study group are presented in Table 5 and Table 6. Statistical significance is important, demonstrated by the $\mathrm{p}$ value $=0.0007$ (for tumoral staging) and $p=0.040$ (for lymph node staging).
Table 5. Distribution of cases according to the pT stage

\begin{tabular}{|c|c|c|}
\hline Stage & $\begin{array}{c}\text { Number of cases } \\
(\mathbf{n}=48)\end{array}$ & $\begin{array}{c}\text { Statistical analysis } \\
(\mathbf{p})\end{array}$ \\
\hline pTis & 1 & \multirow{2}{*}{} \\
\hline pT0 & 1 & \multirow{2}{*}{0,00070} \\
\hline pT1a & 1 \\
\hline pT1c & 5 & \\
\hline pT2 & 16 & \\
\hline pT3 & 12 \\
\hline pT3b & 2 \\
\hline pT4a & 1 \\
\hline pT4b & 9 \\
\hline
\end{tabular}

No distant metastases were identified within the metastasis component. In addition to the TNM staging, an important role is played by the histopathological degree, which is a strong indicator of the prognosis in breast cancer. Thus, within the selected group, there were detected 6 patients in G1 stage, 27 patients in G2 stage, 9 patients in G3 stage, and in 6 patients the degree of differentiation could not be highlighted.

Table 6. Distribution of cases belonging to the $\mathrm{pN}$ stage

\begin{tabular}{|c|c|c|}
\hline Stage & $\begin{array}{c}\text { Number of cases } \\
(\mathbf{n}=\mathbf{4 8})\end{array}$ & $\begin{array}{c}\text { Statistical analysis } \\
(\mathbf{p})\end{array}$ \\
\hline $\mathrm{pN} 0$ & 23 & \multirow{2}{*}{0} \\
\hline $\mathrm{pN} 1$ & 16 & 0,040 \\
\hline $\mathrm{pN} 1 \mathrm{a}$ & 3 \\
$\mathrm{pN} 2$ & 3 \\
\hline $\mathrm{pN} 3$ & 3 & \\
\hline
\end{tabular}

Regarding the final staging of pTNM, the following clinical stages from the studied sample were reported: stage 0 ( 1 case), stage 1 ( 3 cases), stage 2 a (12 cases), stage $2 b$ ( 9 cases), stage $3 a$ (10 cases) and stage $3 b$ (13 cases), with important statistical significance, demonstrated by the value of $p=0.00025$. No cases belonging to stage 4 were recorded. All cases belonging to the current study showed negative resection margins.

Table 7. Distribution of cases according to clinical stages

\begin{tabular}{|c|c|c|}
\hline Stage & $\begin{array}{c}\text { Number of cases } \\
(\mathbf{n = 4 8})\end{array}$ & $\begin{array}{c}\text { Statistical } \\
\text { analysis (p) }\end{array}$ \\
\hline Stage 0 & 1 & \multirow{2}{*}{0} \\
\hline Stage 1 & 3 & \multirow{2}{*}{0,00025} \\
\hline Stage 2a & 12 & \\
\hline Stage 2b & 9 & \\
\hline Stage 3a & 10 & \\
\hline Stage 3b & 13 & \\
\hline
\end{tabular}

In the present study, a variety of morphopathological forms were noted, of which invasive breast cancer of the NST type predominated, with a frequency of $62.50 \%$ of all identified malignant breast tumours. With a proportion of $29.17 \%$, infiltrative ductal carcinomas were the second most common histopathological form of malignant breast tumours. Apocrine carcinoma, solid and cribriform intraductal carcinoma and hypercellular 
mucinous carcinoma were also identified. The $\mathrm{p}$ value is 0.045 , being statistically significant.

Table 8. Distribution of malignant breast tumours

\begin{tabular}{|l|c|c|}
\hline \multicolumn{1}{|c|}{ Type } & $\begin{array}{c}\text { Number of } \\
\text { cases (n=48) }\end{array}$ & $\begin{array}{c}\text { Statistical analysis } \\
\text { (p) }\end{array}$ \\
\cline { 1 - 2 } Apocrine carcinoma & 2 & \multirow{2}{*}{0} \\
\cline { 1 - 2 } Infiltrative ductal carcinoma & 14 & \multirow{2}{*}{0,045} \\
\hline $\begin{array}{l}\text { Solid and cribriform } \\
\text { intraductal carcinoma }\end{array}$ & 1 & \\
\cline { 1 - 2 } Invasive breast cancer (NST) & 30 & \\
\cline { 1 - 2 } $\begin{array}{l}\text { Hypercellular mucinous } \\
\text { carcinoma }\end{array}$ & 1 & \\
\hline
\end{tabular}

The patients of the main group were evaluated according to the presence of immunohistochemical examination and included 4 basic immunohistochemical biomarkers: estrogen, progesterone hormone receptors, HER2 and Ki-67. This examination was performed in 15 cases diagnosed with breast cancer from group A $(n=48)$. Evaluation of the heterogeneity of estrogen receptor expression at the tumour level showed that of the 15 cases, 12 had positive receptors and 3 had negative receptors. Regarding the expression of progesterone receptors at tumour level, 11 cases had positive receptors and 4 cases had negative receptors. In the current study, the immunohistochemical quantification of HER2 was performed for 15 cases, of which in 5 cases HER2 was positive and in 10 cases HER2 was negative. In the case of the Ki-67 biomarker, 11 cases presented receptors in a proportion of $10-30 \%$, and 4 cases presented receptors in a proportion of $40 \%$. Statistically, the differences are significant with a $p$ value $=0.00035$.

Table 9. Distribution of patients according to immunohistochemical examination

\begin{tabular}{|c|c|c|c|}
\hline Immunohistochemistry & Receptors & $\begin{array}{c}\text { Number } \\
\text { of cases } \\
\text { (n=48) }\end{array}$ & $\begin{array}{c}\text { Statistical } \\
\text { analysis (p) }\end{array}$ \\
\hline Estrogen receptors & Positive & 12 & \multirow{3}{*}{} \\
\cline { 2 - 3 } & Negative & 3 & \multirow{2}{*}{0,00035} \\
\hline Progesterone receptors & Positive & 11 & \multirow{2}{*}{} \\
\cline { 2 - 3 } & Negative & 4 & \multirow{2}{*}{5} \\
\hline \multirow{2}{*}{ HER2 receptors } & Positive & 5 & \\
\cline { 2 - 3 } & negative & 10 & \\
\hline \multirow{2}{*}{ Ki-67 } & $10-30 \%$ & 11 & \\
\cline { 2 - 3 } & $40 \%$ & 4 & \\
\hline Not accomplished & - & 33 & \\
\hline
\end{tabular}

In group A, patients aged between 40 and 89 years were studied. The maximum incidence was found in the age group 60-69 years (16 patients), followed in descending order by the age group 50-59 years with 14 patients, the age group 70-79 years ( 9 patients), the group age $40-49$ years ( 5 cases) and age group $80-89$ years (4 patients).

\section{Presentation of the secondary group (B group)}

Analysing the age groups and the duration of hospitalization of the patients who underwent sectorectomy, the following results were obtained: the maximum incidence was reported in the age group 60-69 years (16 cases), followed by the age groups 50-59 years (7 cases), 40-49 / 70-79 years with similar results between them (4 cases) and 80-89 years ( 1 case). The duration of hospitalization showed a dominance of cases that benefited from a hospitalization of 8 days ( 6 cases), and for the rest of the hospitalization days, with an interval between 3 days and 10 days, a constancy of approximately 2 cases was found on the duration of the respective hospitalization. Regarding the results obtained for patients treated by tumorectomy, there is a maximum incidence in the age group 70-79 years (4 cases), followed by the age groups 40-49 / 50-59 years with similar results between them (2 cases), 20-29 / 60-69 / 90-99 with similar results between them (1 case). The duration of hospitalization showed a maximum incidence of cases that were hospitalized over a period of 3 days ( 3 cases), followed by the period of 4 days (2 cases), the interval of 6-19 days presenting a constancy of one case.

Within group B, the staging protocol was established according to the histopathological examination for patients diagnosed with breast cancer, surgically treated by sectorectomy and tumorectomy. For the analysis of the histopathological examination of this group, patients diagnosed with breast cancer for whom the histopathological examination was not printed in the computerized database were excluded. Thus, 17 cases in which sectorectomy was performed and 7 cases that benefited from tumorectomy were analysed. For patients who benefited from sectorectomy, a tumour component was identified for staging, where the maximum incidence was observed at the pT2 stage (9 cases), decreasingly followed by the pT1c stage ( 7 cases) and the pTis stage (1 case). Regarding the lymph node component, the maximum incidence belonged to the pN0 stage ( 8 cases), followed by the pN1 stage ( 7 cases) and the pN2 stage ( 2 cases). Remote metastases did not exist. The frequency of clinical stages in descending order is: stage $2 \mathrm{a}$ ( 8 cases), stage $2 \mathrm{~b}$ ( 4 cases) and stages 1 and $3 a$ with similar results ( 2 cases).

Analysing the patients treated by tumorectomy, a tumour component was identified, having as maximum incidence the pT1c stage ( 4 cases), followed by the pT2 stages ( 2 cases) and pT4b (1 case) and a lymph node component, where 6 cases belonged to the pNO stage, and one case to the $\mathrm{pN} 1$ stage. Also, distant metastases did not exist. Regarding the clinical stages, the incidence of cases belonging to stages 1 and $2 \mathrm{a}$ was similar ( 3 cases), and in stage $3 \mathrm{~b}$, one patient was identified. 


\section{Prevention of surgical site microbiological contamination}

The issue of microbiological contamination is particularly important in breast cancer surgery. First of all, the psychological impact of the scar is a major one, so the surgeon must take all precautions for a cure per primam, without infection and granulation tissue. Secondly, breast cancer surgery is performed in immunosuppressed patients, and the vicinity of the axillary and submammary folds, with abundant commensal microbial colonization, is an additional risk factor. The main etiological agents involved in SSI in breast cancer surgery were Staphylococcus and Streptoccocus spp, with MRSA. The prophylaxis measures commonly used in breast surgery in surgery clinics consist of preoperative skin decontamination over a large area, removal of hair from the axillary region, broad-spectrum antibiotic therapy for anesthetic induction, careful intraoperative hemostasis, installation of aspiration drainage to prevent serum formation, excellent microbial culture media. In the early postoperative period, the daily dressing is practiced respecting the principles of asepsis and antisepsis and disinfection of the skin with solutions of betadine, iodinated alcohol or $70^{\circ}$ alcohol in case of iodine allergy.

After analysing the results of this study, it can be said that the data obtained are in accordance with data from the literature regarding the increased frequency of postmenopausal breast cancer (R. SIEGEL \& al [3]), with a significant increase in the incidence of breast cancer in the age group 50-59 years where 38 cases were identified, with the maximum prevalence in the age group 60-69 years where a number of 41 cases were reported. Analysing the incidence of breast cancer by age groups, in the general group, a $p$ value of 0.00031 was obtained which is statistically significant. Also, a significantly higher percentage of female cases was observed in the study population, the $\mathrm{F}$ : $\mathrm{M}$ ratio being 125:4. The increased number of female cases is due to the hormonal component, estrogens causing the proliferation processes of the breast epithelium and thus influencing the appearance of carcinogenic mutations due to the appearance of an error in the DNA replication (AMANATULLAH \& al [4]).

The treatment of breast cancer is probably one of the most controversial topics in general surgery. It was observed that in the Surgery Clinic II, most patients were treated by modified radical mastectomy $(37.21 \%), 24.81 \%$ of patients benefited from sectorectomy and $8.53 \%$ from tumorectomy. The choice of therapeutic conduct is influenced by several factors such as the results of histopathological, clinical and imaging examinations, as well as patient preference. Jeffrey $\mathrm{Gu}$ et al. conducted a study in 2016 to identify the factors that influence patients' choice between modified radical mastectomy and conservative therapy. A larger number of patients opted for the modified radical mastectomy for the following reasons: the size of the breast tumour, the fear of recurrences after performing conservative therapy, the consequences of conservative surgery, including radiotherapy and possible surgical reoperations (GU \& al [5]).

Regarding the type of mastectomy, 46 MaddenAuchincloss mastectomies and 2 Pattey-Dyson mastectomies were performed within the Surgery Clinic II. The statistical analysis performed suggests that the proportion of cases that benefited from modified radical mastectomy was higher in the age group 60-69 years (16 cases), followed by the age group 50-59 years (14 cases), with no major differences compared to the trend of the patients according to the age group in which the sectorectomy and tumorectomy were performed. Studies conducted in China by Xiaoyuan Bao et al. and by Nai-si Huang et al. claimed that the maximum incidence of the number of modified radical mastectomies was identified in the 50-65 age group. There have been contradictions regarding the age groups in which conservative therapy was practiced, Xiaoyuan Bao et al. arguing that most cases receiving conservative therapy were older than 80 years, and Nai-si Huang et al. obtained a higher incidence in patients under 35 years of age (BAO \& al [6]; HUANG \& al [7]).

Patients who underwent surgery by modified radical mastectomy had an average hospital stay of 7-8 days (the minimum being 4 days and the maximum being 33 days) with a maximum incidence of 8 days. Longer hospital stays were significantly associated with either the presence of comorbidities or more advanced stages of breast cancer. From the perspective of conservative interventions, the hospitalization duration of patients treated by sectorectomy had a maximum incidence at the interval of 8 days, with no major differences between it and modified radical mastectomy, a significant difference being observed in cases treated by tumorectomy who benefited from a duration of hospitalization of 3 days.

The incision of the skin must be made according to the following elements: the location of the tumour, the potentially invaded skin area, the suture and the cosmetic appearance. In the literature, the Stewart's transverse incision is cited as being preferred for the location of the malignant breast tumour in the central quadrant, respectively the Orr oblique incision for the rest of the locations, preferably for tumours located in the superoexternal quadrant (SRIVASTAVA \& al [8]). Axillary dissection remains an important component of breast cancer treated by modified radical mastectomy for curative and diagnostic purposes. This was performed in all cases operated on by modified radical mastectomy. A study by Mahommed Faisal et al. concluded that lymph node dissection is a simple technique that significantly reduces the frequency of postoperative serum formation (FAISAL \& al [9]), this being supported in the current 
study by the small number of cases ( 5 cases out of 48) in which seroma was formed postoperatively. Drainage suppression protocols differ considerably between them, in the current study, the drainage tubes being suppressed approximately 3 days postoperatively in most cases operated by modified radical mastectomy. These results are in agreement with those obtained by George S. Stoyanov et al. which state that apparently the best results in terms of postoperative complications were obtained when the drainage tubes were removed 2-3 days postoperatively or when the amount of fluid drained in the last 24 hours reached less than $50 \mathrm{ml}$ (STOYANOV $\&$ al [10]).

Neoadjuvant chemotherapy aims at decreasing tumour volume in cases with locally advanced evolution, in the present study being instituted in $27.08 \%$ of patients in view of establishing the surgical treatment by performing modified radical mastectomy, results approximately congruent with those obtained by Xiaoyuan Bao et al (BAO \& al [6]).

The location of tumours in the breast, within group A, varies, with the highest frequency being in the superoexternal quadrant $(47.92 \%)$, and the lowest frequency being in the supero-internal quadrant $(4.17 \%)$. The location of tumours in the central quadrant should be considered, with a percentage of $18.75 \%$, because studies in the literature have reported a significantly increased likelihood that tumours be diagnosed at a later stage, with increased size, positive lymph nodes and an increase in mortality rate (RUMMEL \& al [11]).

Histopathological examination has a major impact on therapeutic conduct. In view of this, the modified radical mastectomy resulted in being the surgery of first choice for patients diagnosed with breast cancer in more advanced stages of the disease, respectively stage $3 a$ and $3 b$. Regarding the early stages of breast cancer, it has been noted that conservative therapy is practiced as first intention, studies in the literature stating that conservative therapy is indicated for tumour sizes smaller than $2 \mathrm{~cm}$ (JOOP \& al [12]; MAZILU \& al [13]; PANTEA STOIAN $\&$ al [14]), and other studies allow the practice of this method for tumours smaller than $5 \mathrm{~cm}$ in size after neoadjuvant chemotherapy (DANCIU \& al [15]; SCAUNASU \& al [16]; Merlo [17]). Careful histological evaluation of the resection margins is essential due to the risk of local post-surgical recurrences, being necessary that at the level of the marked margin, no tumour tissue should exist as well as the presence of a margin of at least $1 \mathrm{~mm}$ for the invasive component, given the high incidence rate of invasive breast carcinoma (NST) in both groups (group A and group B) of this study. All cases belonging to the current study showed margins of resection without tumour infiltration.

In breast cancer, paraneoplastic syndromes are rare, but challenging to treat. Endocrine and neurologic syndromes were described, sharing a similar immunological mechanism. Outcomes vary depending upon duration of disease, the therapeutic approach and the responsiveness of the underlying cancer (DRAGHICI $\&$ al [18]; MAZILU \& al [19]; FANOUS \& al [20]).

Surgical site infection in breast cancer surgery can be a challenging complication of breast cancer surgery. The preoperatory antibiotic prophylaxis is widely used in most of so-called clean surgeries, including vascular or plastic interventions, to prevent surgical site contamination with Staphylococcus spp, from the tegument (THROCKMORTON \& al [21]; DAVIS [22]). Interventional studies have shown that MRSA and other multidrug resistant species are responsible for up to one third of surgical wound infections. One the other hand, other studies proved that antibioprophylaxis can be related to increased risk of SSI, because the use of underdosed antibiotics. A $13.2 \%$ rate of SSI with cefazolin 1 gram, $p<0.0001$, and $15.4 \%$ rate of SSI with clindamycin $300 \mathrm{mg}$ or less was encountered by Crawford et al. (C. CRAWFORD \& al [23]) This results is infirmed by other studies, which confirm the efficiency of antibiotic use at anesthesia induction in preventing infections (THROCKMORTON \& al [21]; DAVIS \& al [22]; JONES $\&$ al [24]). Obesity was found to be an important risk factor for SSI in several studies (THROCKMORTON \& al [21]; DAVIS \& al [22]; DE BLACAM \& al [25]). Several mechanisms are incriminated: larger surgical incision to expose and resect the pathological lesion, a thick layer of poor perfused tissue, disturbances in immune system. Smoking and diabetes are also associated with increased rate of surgical wound infections. Good infection-control policies, including preoperatory antibioprophylaxis and the use of good-quality medical devices (e.g. surgical drains), extending infection control measures outside surgical field can improve outcomes.

There is a significant impact of breast cancer on QoL in long-term breast cancer survivors. Offer social, psychological and spiritual support to these patients to reduce the negative impact of the disease (CIUFU \& al [26]; STANA \& al [27]; MAZILU \& al [28]; NITIPIR $\&$ al [29]; CHOPRA \& al [30]).

\section{Conclusion}

The most commonly used surgical technique in the treatment of breast cancer is modified radical mastectomy, due to the fact that it allows the removal of both the main tumour mass and the adjacent glandular tissue suspected of infiltration and multifocality of the process and an adequate axillary lymph node dissection, considerably reducing the local recurrence rate compared to other existing surgical techniques in the treatment of breast cancer.

Cases diagnosed with breast cancer increased progressively during the study period, most cases being 
diagnosed in 2017. The increased frequency of breast cancer occurred in adulthood with the maximum prevalence in the age group 60-69 years, also the pathology dominated in frequency in females and the patients came predominantly from urban areas.

Most patients opted for a modified radical mastectomy. Of these, $95.83 \%$ were of Madden-Auchincloss type and only $4.17 \%$ were of Pattey-Dyson type. The Madden type remains the standard therapeutic decision for breast cancer, the proportion of cases operated by this method being higher in the 60-69 age group. The duration of hospitalization of cases operated by modified radical mastectomy was on average 7-8 days, the longer durations being associated with the presence of comorbidities and / or with advanced stages of breast cancer.

Regarding the type of incision, the Orr oblique incision was preferred compared to the Stewart transverse one, because it allows a better axillary access for the lymph node dissection which is an important component of the mastectomy.

Surgical drainage should be initiated immediately because it plays an important role in reducing the risk of seroma formation which has been shown to be the most common postoperative complication occurring in $10.42 \%$ of group A cases.

Cases diagnosed with locally advanced breast cancer were converted into operable by neoadjuvant therapy because these patients were immunohistochemically classified in luminal group A with positive estrogen receptors, positive progesterone receptors, HER2 negative and low Ki-67.

Modified radical mastectomy is the first choice surgery for patients diagnosed with breast cancer in more advanced stages of this disease, compared to conservative therapy which is indicated in the early stages of the disease, being limited by the size of breast tumours, having as upper limit the size of $2 \mathrm{~cm}$ (tumorectomy), respectively $5 \mathrm{~cm}$ (sectorectomy).

Following the histological evaluation of the cases considered in this study, it was concluded that the resection margins were negative in all patients in group A. Both groups had an increased incidence of invasive breast cancer (NST), with a medium degree of tumour differentiation.

\section{Acknowledgements: None}

Note: Andrei Moisin, Dragos Serban and Ciprian Tanasescu are all main authors and contributed equally to this manuscript.

\section{References}

1. N. ANGELESCU. Tratat de patologie chirurgicală, București. Editura Medicală, 1163-1212 (2003). N. ANGELESCU. Tratat de patologie chirurgicală, București. Editura Medicală, 1163-1212 (2003).

2. G. MITULESCU, I. POPESCU, M. BEURAN. Manual de chirurgie. Editura Universitară Carol Davila, București, Vol. I: 311-329, (2007).

3. R. SIEGEL, K. MILLER, A. JEMAL. Cancer statistics 2018, CA. Cancer Journals for Clinicians, 68: 7-30 (2018).

4. D.F. AMANATULLAH, J.S. TAMARESIS, P. CHU et al. Local estrogen axis in the human bone microenvironment regulates estrogen receptor-positive breast cancer cells. Breast Cancer Research : BCR, 19:121 (2017).

5. J. GU, G. GROOT, L. HOLTSLANDER, R. ENGLERSTRINGER. Understanding Women's Choice of Mastectomy Versus Breast Conserving Therapy in Early-Stage Breast Cancer. Clinical Medicine Insights Oncology, 11(1):1-7 (2017).

6. X. BAO, K. SUN, X. TIAN et al. Present and changing trends in surgical modalities and neoadjuvant chemotherapy administration for female breast cancer in Beijing, China: A 10-year (2006-2015) retrospective hospitalization summary report-based study. Thoracic Cancer, 9(6):707-717 (2018).

7. N. HUANG, M. LIU, J. CHEN et al. Surgical management of breast cancer in China: A 15-year single-center retrospective study of 18,502 patients. Fudan. PQ, ed. Medicine. 95(45):e4201. (2016).

8. V. SRIVASTAVA, S. BASU, V.K. SHUKLA. Seroma formation after breast cancer surgery: what we have learned in the last two decades. J Breast Cancer, 15(4):373-380 (2012).

9. M. FAISAL, S.T. ABU-ELELA, W. MOSTAFA, O. ANTAR. Efficacy of axillary exclusion on seroma formation after modified radical mastectomy. World Journal of Surgical Oncology. 14:39 (2016).

10. G.S. STOYANOV, D. TSOCHEVA, K. MARINOVA, E. DOBREV et al. Drainage after Modified Radical Mastectomy - A Methodological Mini-Review. Cureus. 9(7):e1454, (2017).

11. S. RUMMEL, M.T. HUEMAN, N. COSTANTINO, C.D. SHRIVER et al. Tumour location within the breast: Does tumour site have prognostic ability? Ecancer medical science, 9:552 (2015).

12. J. VAN DONGEN, A.C. VOOGD, I. S. FENTIMAN, C. LEGRAND et al. Long-Term Results of a Randomized Trial Comparing Breast-Conserving Therapy With Mastectomy: European Organization for Research 
and Treatment of Cancer 10801 Trial, JNCI: Journal of the National Cancer Institute, 92 (14): 11431150 (2000).

13. L. MAZILU, A.I. SUCEVEANU, D. TOMESCU et al. Optimizing the Indication for Breast-Conservative Surgery (BCS) in Patients with Locally-Advanced Breast Cancer. Chirurgia, 108 (4): 478-481 (2013).

14. PANTEA STOIAN, R. HAINAROSIE, C. PIETROSANU et al. Modern concepts in non-surgical esthetics; a review. JMMS, 6(2): 190-195 (2019).

15. R. DANCIU, C.N. MARINA, V. ARDELEANU, R. MARIN. Breast implant illness: a step forward in understanding this complex entity and the impact of social media. J Mind Med Sci. 6(2): 351-355 (2019).

16. R.V. SCĂUNAȘU, S. VOICULESCU, B. POPESCU, R. POPA et al. Depression and breast cancer; postoperative short-term implications. J Mind Med Sci. 5(1): 82-84 (2018).

17. E.M. MERLO. Opinion Article: The role of psychological features in chronic diseases, advancements and perspectives. Mediterranean Journal of Clinical Psychology, 7(3) (2019).

18. 18.T. DRAGHICI, L. NEGREANU, O.G. BRATU, A. PANTEA STOIAN et al. Paraneoplastic syndromes in digestive tumors: a review, Romanian Biotechnological Letters, 24(5): 813-819 (2019).

19. L. MAZILU, D.L. STANCULEANU, A.D. GHEORGHE. Incidence of chemotherapy-induced peripheral neuropathy in cancer patients in clinical practice, Farmacia, 67(3): 472-476 (2019).

20. FANOUS, P. DILLON. Paraneoplastic neurological complications of breast cancer. Exp Hematol Oncol, 5:29 (2016).

21. A.D. THROCKMORTON, L.M. BADDOUR, T.L. HOSKIN, J.C. BOUGHEY et al. Microbiology of surgical site infections complicating breast surgery. Surgical Infections. 11(4):355-359 (2010).

22. G.B. DAVIS, M. PERIC, L.S. CHAN, A.K. WONG et al. Identifying risk factors for surgical site infections in mastectomy patients using the National Surgical Quality Improvement Program database. The American Journal of Surgery, 205(2):194-199 (2013).

23. C.B. CRAWFORD, J.A. CLAY, A.S. SEYDEL, J.A. WERNBERG. Surgical Site Infections in Breast
Surgery: The Use of Preoperative Antibiotics for Elective, Nonreconstructive Procedures. Int J Breast Cancer. 2016; 2016:1645192.

24. D.J. JONES, F. BUNN, S. BELL-SYER. V. Prophylactic antibiotics to prevent surgical site infection after breast cancer surgery. Cochrane Database of Systematic Reviews, 3 (2016).

25. C. DE BLACAM, A.A. OGUNLEYE, A.O. MOMOH, S. COLAKOGLU et al. High body mass index and smoking predict morbidity in breast cancer surgery: a multivariate analysis of 26,988 patients from the national surgical quality improvement program database. Ann Surg.; 255(3):551-5 (2012).

26. A.N. CIUHU, A.M. PANTEA-STOIAN, C. NITIPIR. Assessment of cachexia in cancer patients with advanced disease, Conference: $3^{\text {rd }}$ International Conference on Interdisciplinary Management of Diabetes Mellitus and its Complications (INTERDIAB) Location: Bucharest, Romania Date: Mar 02-04, 2017, INTERDIAB 2017: DIABETES MELLITUS IN INTERNAL MEDICINE, Book Series: International Conference on Interdisciplinary Management of Diabetes Mellitus and its Complication, pp. 137-139 (2017).

27. D. STANA, O. GRAMESCU, G. SIMION, A.M. DASCALU. Giant malign ocular melanoma treated by selective arterial embolization and exenteration. Case report, The Medical-Surgical Journal, 124(3): 441-447 (2020)

28. L. MAZILU, D.L. STANCULEANU, A.D. GHEORGHE et al. Chemotherapy and other Factors Affecting Quality of Life in Non-Small Cell Lung Cancer (NSCLC) Patients, Revista De Chimie 70(1): 33-35 (2019).

29. C. NITIPIR, C.C. DIACONU, C. ORLOV et al. The Necessity of Nutritional Intervention in the Oncological Patient. What is the Evidence? Conference: $35^{\text {th }}$ Balkan Medical Week on Healthy Ageing An Endless Challenge Location: Athens, GREECE Date: SEP 25-27, 2018, Proceedings Of The 35th Balkan Medical Week, 133-137 (2018).

30. CHOPRA, K.M. KAMAL. A systematic review of quality of life instruments in long-term breast cancer survivors. Health Qual Life Outcomes 10, 14 (2012). https://doi.org/10.1186/1477-7525-10-14 